\title{
An Investigation into Ambiguity Tolerance in Iranian Senior EFL Undergraduates
}

\author{
Amin Marzban (Corresponding author) \\ Department of English, University of Isfahan, Isfahan, Iran \\ E-mail: a_marzban_eng@yahoo.com; amin.marzban@shamimdanesh.com \\ Hossein Barati \\ Department of English, University of Isfahan, Isfahan, Iran \\ E-mail: h.barati@gmail.com \\ Ahmad Moinzadeh \\ Department of English, University of Isfahan, Isfahan, Iran \\ E-mail: moin@fgn.ui.ac.ir
}

Received: August 29, 2011

Accepted: September 26, 2011

Published: January 1, 2012

doi:10.5539/elt.v5n1p76

URL: http://dx.doi.org/10.5539/elt.v5n1p76

\begin{abstract}
The present study aimed to explore how tolerant of ambiguity Iranian EFL learners at university level are and if gender plays a role in this regard. To this end, upon filling in the revised SLTAS scale of ambiguity tolerance 194 male and female Iranian teacher trainees were assigned to three ambiguity tolerance groups; namely, high, moderate and low. Cluster analysis of the SLTAS scores indicated that Iranian EFL learners were mostly moderate as far as tolerance of ambiguity was concerned. Examining the gender differences through an independent sample t-test manifested that female participants were less tolerant of ambiguity than their male peers. Also, the differences between the expected and observed number of participants categorized in the three AT groups were non-significant undermining the role of gender as a moderator variable in assigning participants to AT groups and further approving of SLTAS validity. Implications for classroom practice are presented in the light of findings. The results are helpful in syllabus design and teaching methodology.
\end{abstract}

Keywords: Ambiguity tolerance (AT), Gender difference, Individual characteristics, Teacher training

\section{Introduction and Background of the Study}

Ambiguity tolerance is one of the variables of individual characteristics that has been defined as the perception of inadequate information in order to clearly understand stimuli. This process incorporates a range of individual's reactions extending along a continuum from total agreement to total disagreement (McLain, 1993). The specific trait of AT can be assumed as the reflections of people personality and would affect many aspects of people's life, learning and proficiency of learners (Ely, 1989). Thus, tolerance of ambiguity is commonly known to play a decisive role in various aspects of language performance and learners' beliefs about learning (e.g. reading comprehension and translation) (Erten and Topkaya, 2009; Ashouri and Fotovatnia, 2010).

An awareness of the impact of AT as a psychological construct on EFL learning is of great importance and would result in teachers' modifications in planning and execution of lessons in order to better help the students' overcome psychological barriers. It is therefore deemed necessary to look for possible differences in ambiguity tolerance among learners in order to minimize the gap in teacher- learner interaction and the amount of attention which is paid to important individual traits in classroom context.

Studies addressing ambiguity tolerance have commonly focused on general language achievement and mostly concern ESL contexts (e.g. Chapelle, 1983). Recently, there has been more interest in studies on affective variables in skill specific domains (Kondo-Brown, 2006). Nevertheless, there has been little effort made to investigate the psychological trait of AT in Iranian EFL context where teachers commonly ignore the significance of the role such traits play in language learning. The present study through using survey methodology was prompted by the desire to 
understand AT in relation to factors like gender. It can act as a step forward in making teachers aware of the importance of individual characteristics in EFL learning contexts.

Below is presented a brief review of related studies, followed by a description of the research methodology and findings. Upon discussing the findings, conclusions are drawn and suggestions are made with regard to pedagogical perspectives.

\section{Related Research}

\subsection{Ambiguity Tolerance Issues}

A substantial body of research in AT studies has been devoted to the definition of ambiguity and tolerance as two related concepts in language learning. The concept of ambiguity has been variously defined throughout the literature. Regarding the number and nature of cues available in given contexts and stimuli, insufficient information about a context, lack of cues or at times too many of them can result in ambiguous situations (McLain, 1993; Budner, 1962). Kazamina (1999: 69) also maintained that ambiguity is marked by "novelty, complexity, insolubility and shortage of structure". Tolerance of ambiguity, then, can be a reflection of our personality which is the same as acceptance of above-mentioned ambiguous situations whereas intolerance assumes uncertainties and unclear meanings as potential sources of discomfort (Norton, 1975; Ely, 1989; Ehrman, 1993; 1994).

As for ambiguous situations in language learning, both Linguistic input and cultural knowledge is able to create such situations either while group work in a classroom context (Ely, 1995) or individually in self-instructed language study (White, 1999). Students are known to face shortage of information, multiple meanings, vagueness, and so on when encountering new lexical and grammatical structures (Chapelle and Roberts, 1986; Grace, 1998). Such problematic situations should be removed to help the learning process move more smoothly. For instance, EFL learners are expected to get rid of vagueness (i.e. ambiguity) through using more optional words and as a result assisting the audience to better comprehend the given input (Sepassi and Marzban, 2005).

\subsection{Ambiguity Tolerance (AT) and Language Learning Studies}

Should AT be defined as the acceptance of uncertainties (Ely, 1989), this can be applied to the learning context as "an ability to deal with ambiguous new stimuli without frustration or without appeals to authority which allows for indeterminate rather than rigid categorization" (Ellis, 1994: 518). Thus, those learners with higher tolerance of ambiguity are expected to deal with learning a new language with its uncertainties and unknown structural and cultural aspects more easily. Mclain (1993), for instance, reports students with high tolerance of ambiguity to take more risks and be open to change. Such type of students show endurance on tasks and upper levels of achievement (Chapelle, 1983; Naiman, Froclich and Todesco, 1975). Similarly, ambiguity can be accommodated so that it does not impede progress in a language task (White, 1999). Erten and Topkaya (2009) who categorized Turkish EFL learners into three AT groups; namely, high, moderate and low, also found that while the majority were of low level in their tolerance of ambiguity, students' AT, their self-perceived success, and received strategy training correlated significantly. They also stressed the role of learner training in improving tolerance of ambiguity.

An individual's level of AT can influence the use of some language learning strategies. Ehrman and Oxford (1990) classified learners into two types; namely, those with intuitive types of personalities who often have higher levels of AT and those with sensing type of personalities with lower AT levels. The former type of learners were reported to guess from context most of the time whereas the latter type were more likely to avoid such a strategy. A more recent case study of two Japanese learners of English, too, laid proof on the impact of AT on the use of strategies. Nishimo's (2007) study showed that the first student who felt comfortable with ambiguity, i.e. having high levels of tolerance, preferred to fulfill reading tasks without using a dictionary while the second student with less tolerance relied heavily on looking up the unknown words in order to minimize ambiguity.

Ehrman $(1993 ; 1999)$ specified three different levels for the operation of AT: intake; tolerance of ambiguity proper; and accommodation. Learners are enabled to receive linguistic input with all its unknown elements on the first level and hold contradictory information without necessarily rejecting one of the incomplete elements on the second level. The last level which closely relates to constructivist psychology (Piaget, 1967) involves self adaptation based on the new material. Within this level the learner integrates new information with the existing schemata while restructuring the latter.

Studies on ambiguity tolerance has continuously stressed its relationship to issues such as language achievement (Chapelle and Roberts, 1986; Naiman, et. al. 1978; Lori, 1990; Shemshadi and Shaeiri, 2005), various personality traits (Ehrman and Oxford, 1990), reading comprehension (El-Koumy, 2000; Erten and Topkaya, 2009) and translation belief (Ashouri and Fotovatnia, 2010). The results of above mentioned studies mostly suggest that there may be a positive correlation between the degree of AT and the progress in the stated psychological and pedagogical 
areas. For instance, success in multiple choice grammar tests, dictation tests, partially in speaking tests, listening comprehension and imitation tasks indicated such positive relationships between AT and language achievement (Chapelle and Roberts, 1986; Naiman et. al. 1978). However, Ashouri and Fotovatnia (2010), illustrated that ambiguity tolerance, as an individual characteristic, had no effect on translation belief.

\subsection{How Important is AT in Language Learning?}

While tolerance of ambiguity remains to be an inevitable individual characteristic which is believed to influence many psychological and pedagogical decisions and according to reviews above relates to achievement in language learning, there are concerns about over-tolerance. This is worrisome because high levels of tolerance may have the reverse effect on the process of language learning, i.e. some kind of unquestioned acceptance. Conversely, lack of sensitivity to ambiguous linguistic data would result in early pidginization or fossilization. (Ely, 1995; Kazamina, 1999).

Thus it seems there is overall consent over the issue that a moderate level of ambiguity tolerance can assist effective language learning to a greater degree. That 's why Ely reiterates " the ideal case, of course, is that of the learner who is neither inhibited by low tolerance of ambiguity nor oblivious to linguistics subtleties" (1995: 93). However, it is yet a matter of controversy as to what is exactly meant by mid point (Kazamina, 1999). It is hereby concluded that more research is needed to clarify the nature of AT and the degree to which its existence can promote language learning.

\section{Study}

\subsection{Aim of the Study}

The present study aimed to understand how tolerant English undergraduate EFL learners are in their last year of studies at Shiraz Azad University along with exploring the relationship between ambiguity tolerance and gender. The following questions were addressed:

1. How tolerant are Iranian university undergraduates of ambiguity?

2. Are males and females any different in terms of their tolerance of ambiguity?

\subsection{Setting and Participants}

The study was carried out at Islamic Azad University in Shiraz, Department of English, where English translation and teaching courses are offered at BA level. The data was collected in the second semester of the 2010-2011 academic year during normal class hours. It took the participants about 10 minutes to fill in the Second Language Tolerance of Ambiguity Scale (SLTAS).

Out of 245 (186 full time / 59 part time) senior teacher trainees at Islamic Azad University in Shiraz, Iran, 205 participated in the study. They were also homogenized through an Oxford Placement Test by selecting those whose scores on the test were one SD above and one SD below the mean in order to counter any effect of proficiency level on the performance of participants on the scale.

Some participants were excluded from data analysis due to careless coding, bringing the final number of students to 194. As for the demographic information about the participants, the majority of the 194 undergraduates was females as compared to male students ( $160-82.4 \%$ vs. $34-17.5 \%)$. The justification for the lower number of males as compared to females in this study is that female candidates commonly outnumber the opposite gender in selecting English as their major in Iranian university entrance exams. This has long been observed in both state and private universities throughout the country and major cities such as Shiraz, Iran. It also been witnessed in all four intakes of English major who study simultaneously at the university (i.e. freshmen through senior students) where the study was carried out. All the students of 1386 intake at Shiraz Azad University was therefore treated like an intact group in this study. The students had mean age of $21.63(\mathrm{SD}=1.41)$ which represents a close age band.

\subsection{Instrument \& Procedure for Data Collection}

The Second Language Tolerance of Ambiguity Scale (SLTAS) (Ely, 1995) was used for collecting the data which embedded some demographic questions. Even though, there are other scales for measuring AT available in the literature (e.g., Budner, 1962; Norton, 1975; McLain 1993), SLTAS was preferred to other similar scales since is known to be the only formally published one especially designed for measuring ambiguity tolerance in language learning to the best of the authors' knowledge.

The version of SLTAS used in this study has 12 items with a five point likert scale that is consistent with the modification Erten and Topkaya (2009) and Dornyei (2001) made in the original version of the scale; namely, inserting a new anchor (not sure) into it in order not to make students take a forced decision between a negative and 
positive choice. The items available are meant to measure students' agreement level with statements depicting intolerance of ambiguity in given situations. This version of the SLTAS as shown in Table 1 was previously reported to have high internal consistency (Kazamina, 2000).

\section{Data Analysis}

In order to answer the first research question, participants were reminded, before filling in the scale, that the items in SLTAS sought their reactions to statements describing intolerance of ambiguity, thus disagreeing with an item is a sign of tolerance in a reverse manner. Likewise, a mean of 3.00 which equals the inserted anchor of not sure can be interpreted as the borderline of tolerance/intolerance. Any value above this borderline will point to lower levels of tolerance while those below it will suggest more degree of tolerance depending on their distance to mean score of 3.00. The study, however, takes a composite score of ambiguity tolerance into consideration instead of dealing with individual items of the scale as separate indicators of ambiguity. Table 1 presents students` mean scores from the SLTAS.

As a rule of thumb, a classification can be made either through the calculation of each student's ambiguity scores and putting him in an ambiguity group ranging from high to low tolerance or running the reductionist statistical technique of cluster analysis which groups the participants according to their scores on one or more variables( Hatch and Lazaraton, 1991).

An item-by-item analysis of the scale revealed a mean range between 3.89 and 2.00, which leads us to the fact that the total score 3.09 should not result in stereotyping since people can be categorized according to their different levels of ambiguity tolerance; namely, low, moderate and high (Ehrman, 1999; Ely, 1995; El-Koumy, 2000). Thus, in order to place the participants in the suggested three ambiguity tolerance groups, a further K-means cluster analysis on SPSS was performed. The results indicated that the participants could be categorized into three distinct clusters of students according to their tolerance scores (See Table $2 \& 3$ ). Also, an additional analysis of variance (ANOVA) between the three identified AT groups further confirmed that the obtained clusters were distinct from one another. The differences can be seen in Table 4 .

Regarding the second research question, an independent samples t-test was conducted to see whether there are any gender differences. As can be seen in Table 5, even though both groups had a mean score that is above the mid-point expressing lower tolerance of ambiguity, female participants appeared to be less tolerant of ambiguity than their male peers as the mean of female students was closer to higher values than 3 which was considered to be the borderline of tolerance/intolerance. A closer look at the distribution of both genders to each of the previously identified tolerance groups and the analysis of frequency confirmed the results from the t-test. Also a Chi-Square run to check for the possible differences between the number of observed and expected male and female participants in three groups of ambiguity tolerance indicated no significance (See Table 7).

\section{Findings and Discussion}

\subsection{How Tolerant/Intolerant are Iranian EFL Learners of Ambiguity?}

The participants reported a level of tolerance almost at the borderline of tolerance/intolerance, actually mildly above it (mean=3.09). This was congruent with some findings in the literature e.g. what Kazamina (1999) found with Greek civil servants. This, too, supports Oxford 's claim as to how language learning can be an ambiguous and stressful experience with its uncertainties (Oxford, 1999). The level of tolerance obtained here shows that Iranian university level students, on average, will not exhibit high tolerance/intolerance of ambiguity, neither accepting input without scrutiny nor prevented from understanding through incomplete linguistic information.

Descriptive statistics combined with cluster analysis and analysis of variance lead us to three different groups of students according to their ambiguity tolerance. An important proportion of participants $(\mathrm{f}=110 ; 56.7 \%)$ exhibited moderate level of AT (mean $=38.2$ ), a lower proportion $(\mathrm{f}=60 ; 30.9 \%)$ had low levels of AT (mean= 52.5) and finally a small proportion ( $\mathrm{f}=24 ; 12.4 \%$ ) manifested high levels of AT (mean=19.5). This implies that, expectedly, there are variations among language learners and they will not always tolerate ambiguity to the same degree.

\subsection{Are Females and Males Different in Terms of Their Tolerance of Ambiguity?}

Gender is believed to relate to many affective constructs in the process of language learning. Thus, looking for possible gender differences in the level of ambiguity tolerance would aid the understanding of male and female abilities as controlled by psychological traits like AT.

The detailed frequency analysis in Table 6 indicates that along with the mean differences in ambiguity scores, large proportions of female participants in this study fell into low (29.4\%) and moderate (58.8\%) tolerance groups while the same figures were rather lower with male students (38.2\% and $47.1 \%$ respectively). 5 out of 34 male students 
(14.7\%) reported high tolerance of ambiguity while the proportion of female students who fell into the same tolerance group was $11.9 \%(\mathrm{f}=19)$. The overall findings confirm the higher levels of intolerance; namely, lower levels of tolerance, among female students both in this study and similar works which attempted to see how tolerance of ambiguity affects language learning (Erten \& Topkaya, 2009).

Finally, the results from the Chi-Square indicated that if gender can be assumed as a moderator variable in the present study, it could not have affected the placement of subjects in the three AT groups, that is male and female participants were likely to be put in the AT groups to the same degree. This obviously lays further proof to the validity of the SLTAS scale of ambiguity tolerance. (See Table 7).

Gender differences in ambiguity tolerance have not received much attention in language studies. Nevertheless, there are studies mostly from affective/cognitive domains that have elaborated on the issue. For instance, men were reported to be less tolerant than women and were shown to have more discomfort both grammatically and lexically as compared to women (Fukuchi \& Sakamoto, 2005). Nevertheless, it was maintained that ambiguity tolerance is often less common among men than women.

The outcome of research in the realm of learning styles and personality traits, however, indicates more similarity to findings that report the reverse and are congruent with the results of present study and some other similar ones (e.g. Erten and Topkaya, 2009). Males were often reported to be less field-dependent than females and are thus more strongly capable of finding details from tricky backgrounds more effectively than their female peers (Oxford, 1993). As far as reflection vs. impulsivity distinction is concerned, girls were shown to be more reflective than boys; namely, tending to think details when making a decision while males tend to be more impulsive; namely, being impatient as a result of uncertainty in decision making (Larsen-Freeman and Long, 1991). This further indicates that females are more closure oriented and therefore less tolerant of ambiguity when confronted with language learning issues. This way, males would find language learning less discomforting than females.

\section{Conclusion}

The present study aimed to explore the nature of ambiguity tolerance in EFL learners and its likely relationships with personal variables like gender. The first drawn conclusion is that the Iranian university level EFL learners were mostly shown to have a moderate level of ambiguity tolerance in language learning. The cluster analysis also approved of this finding where the majority of the learners were placed in either moderate or low AT groups. Thus indicating that only a small number of the participants were of high AT; namely, assigned to low ambiguity intolerance group. Therefore, it can be suggested that learners in an EFL context are generally either intolerant of ambiguity or having moderate levels of this trait.

Exploring gender differences in relation with ambiguity tolerance revealed that females are less tolerant of ambiguities (i.e. more intolerant of AT) in the language learning context than their male classmates. This shows that females' intolerance of ambiguities in language would result in studying more closely to look for the details; a useful strategy applied to complex issues in the process of language learning. A further Chi-square pointed to the fact that the differences between the number of observed and expected male and female participants in each ambiguity group were non-significant which leads us to realize that gender has not contributed to categorization of EFL learners in a certain level of AT. This way SLTAS further proves its validity.

The pedagogical implication of the present study is the interference of AT levels with the learning process in the first place. A certain level of intolerance (e.g. high) can act as a kind of hindrance in the process of language learning. Should teachers be regarded as influential members in learning contexts, they are expected to play a role in assisting learners in their efforts to reach greater success in language learning specially when ambiguities are confronted. This very role is manifested in teachers' responsibility to promote students' awareness of methods, procedures and teaching content as well. As Dornyei (2005) explained, learners feel more self-confident and motivated in the language classroom if they are informed about procedures applied to classroom context which would help lower tolerance of ambiguity.

The teacher trainees who participated in this study were mainly found to be either moderate or low as far as AT was concerned. Since they are expected to assist their future students in handling ambiguities, it turns out to be quite essential for them to increase their own tolerance of ambiguity at least before starting their professional teaching career. Oxford and Ehrman (1988) proposed a list of learning strategies which proved to promote AT (e.g. translation and comprehension of texts without a dictionary, teaching affixation and derivation issues, etc.) that can be used by such teacher trainees to overcome ambiguities where they appear disruptive. Probably, this very need is of greater importance for the female teacher trainees in their future ventures.

As for limitations of the present study, it is worth mentioning that the participants of the present study came from 
senior EFL undergraduates in one university. Thus, one would need to focus on larger samples from various educational contexts in further research. Second, a single ambiguity tolerance scale was employed in the present paper while it would yield interesting results if the subjects are exposed to other scales of AT measurement and a comparison is made among them for EFL learners of other academic levels.

\section{References}

Ashouri, A. F., \& Fotovatnia, Z. (2010). The Effect of Individual Differences on Learners' Translation Belief in EFL Learning. English Language Teaching, 3(4), 228-236

Budner, S. (1962). Intolerance of ambiguity as a personality variable. Journal of Personality, 30, 29-50

Chapelle, C., \& Roberts, C. (1986). Ambiguity tolerance and field independence as predictors in English as a second language. Language Learning, 36 (1), 27-45. http://dx.doi.org/10.1111/j.1467-1770.1986.tb00367.x

Dornyei, Z. (2005). The psychology of the language learner. London: Lawrence Earlbaum Associates.

Ehrman, M., \& Oxford, R. (1990). Adult language learning styles and strategies in an intensive training setting. Modern Language Journal, 74 (3), 311-327. http://dx.doi.org/10.2307/327627

Ehrman, M. E. (1993). Ego boundaries revisited: toward a model of personality and learning. In Alatis J.E. (ed.), Strategic interaction and language acquisition: theory, practice, and research. Washington, DC: Georgetown University.

Ehrman, M. E. (1994). Weakest and strongest learners in intensive language training: a study of extremes. In Klee C. A. (ed.), Faces in a crowd: the individual learner in multisection courses. Boston: MA, Heinle \& Heinle.

Ehrman, M. (1999). Ego boundries and tolerance of ambiguity in second language learning. In Arnold, J. (ed.), Affect in language learning. Cambridge: Cambridge University Press.

El-Koumy, A. S. A. (2000). Differences in FL reading comprehension among high-, middle-, and low-ambiguity tolerance students. Paper presented at the national symposium on English language teaching in Egypt, March 21-23, 2000. Ain Shams University, Egypt (ED 445534).

Ellis, R. (1994). The study of second language acquisition. Oxford: Oxford University Press.

Ely, C. (1989). Tolerance of ambiguity and use of second language strategies. Foreign Language Annals, 22, 437-445. http://dx.doi.org/10.1111/j.1944-9720.1989.tb02766.x

Erten, I. H., \& Topkaya, E. Z. (2009). Understanding tolerance of ambiguity of EFL learners in Reading Classes at tertiary level. Novitas-Royal, 3(1), 29-44

Fukuchi, N. T., \& Sakamoto, R. (2005). Affective dimensions of the Japanese foreign language learner: implications for psychological learner development in Japan. Journal of Multilingual and Multicultural Development, 26(4), 333-350

Grace, C. (1998). Personality type, tolerance of ambiguity, and vocabulary retention in CALL. CALICO Journal, 15(1-3), 19-46

Hatch, E., \& Lazaraton, A. (1991). The research manual: Design and statistics for applied linguistics. Boston, MA: Heinle \& Heinle.

Kazamina, V. (1999). How tolerant are Greek EFL learners of foreign language ambiguities. Leeds Working Papers in Linguistics, 7, 69-78. [Online] Available: http://www.leeds.ac.uk/linguistics/WPL/WP1999/kazamina (February 11, 2009)

Kondo-Brown, K. (2006). Affective variables and Japanese L2 reading ability. Reading in a Foreign Language, 18(1), 55-71

Larsen-Freeman, D., \& Long, M. (1991). An introduction to second language acquisition research. London: Longman.

McLain, D. L. (1993). The MSTAT-I: A new measure of an individual's tolerance for ambiguity. Educational and Psychological Measurement, 53, 183-189. http://dx.doi.org/10.1177/0013164493053001020

Naiman, N., Frohlich, M., \& Todesco, A. (1975). The good language learner; TESL Talk, 6, 58-75

Naiman, N., Frohlich, M., Stern, H., \& Todesco, A. (1978). The good language learner. Toronto: Ontario Institute for Studies in Education.

Nishimo, T. (2007). Beginning to read extensively: a case study with Mako and Fumi. Reading in a Foreign Language, 19(2), 76-105 
Norton, R. W. (1975). Measurement of ambiguity tolerance. Journal of Personality Assessment, 39, 607-619. http://dx.doi.org/10.1207/s15327752jpa3906-11

Oxford, R., \& Ehrman, M. E. (1988). Ants and grasshoppers badgers and butterflies: Qualitative exploration of adult language learning styles and strategies. Paper Presented at the Symposium on Research Perspectives on Adult Learning, Ohio State University.

Oxford, R. (1993). Instructional implications of gender differences in language learning styles and strategies. Applied Language Learning, 4, 65-94

Oxford, R. (1999). Anxiety and the language learner: new insights. In Arnold, J. (ed.), Affect in language learning. Cambridge: Cambridge University Press.

Piaget, J. (1967). Six psychological studies. New York: Random House.

Sepassi, F., \& Marzban, A. (2005). On the effects of economization and disambiguation in the production of EFL learners. Asian EFL Journal, 2, Article 2. [Online] Available: www.asian-efl-journal.com (March18, 2011)

Shemshadi, A., \& Shaeiri, M. R. (2005). The Impact of AT Change on Language Proficiency of EFL Learners. Danshvar Raftar, 10, 79-84

White, C. (1999). Expectations and emergent beliefs of self-instructed language learners. System, 27, $443-457$. http://dx.doi.org/10.1016/S0346-251X(99)00044-5

Table 1. Ambiguity Tolerance Scores from SLTAS

\begin{tabular}{|c|c|c|c|}
\hline Item & $\mathrm{N}$ & Mean & $\mathrm{SD}$ \\
\hline $\begin{array}{l}\text { 1. When I'm reading something in English, I feel impatient when } \\
\text { I don't totally understand the meaning }\end{array}$ & 194 & 3.12 & 1.37 \\
\hline $\begin{array}{l}\text { 2. It bothers me that I don't understand everything the teacher } \\
\text { says in English }\end{array}$ & 194 & 3.77 & 1.13 \\
\hline $\begin{array}{l}\text { 3. When I write English compositions, I don't like it when I can't } \\
\text { express my ideas exactly }\end{array}$ & 194 & 3.80 & 1.10 \\
\hline $\begin{array}{l}\text { 4. It is frustrating that sometimes I don't understand completely } \\
\text { some English grammar }\end{array}$ & 194 & 3.86 & 1.10 \\
\hline $\begin{array}{l}\text { 5. I don't like the feeling that my English pronunciation is not } \\
\text { quite correct }\end{array}$ & 194 & 3.89 & 1.12 \\
\hline $\begin{array}{l}\text { 6. I don't enjoy reading something in English that takes a while } \\
\text { to figure out completely }\end{array}$ & 194 & 3.38 & 1.21 \\
\hline $\begin{array}{l}\text { 7. It bothers me that even though I study English grammar some } \\
\text { of it is hard to use in speaking and writing }\end{array}$ & 194 & 3.67 & 1.19 \\
\hline $\begin{array}{l}\text { 8. When I'm writing in English, I don't like the fact that I can't } \\
\text { say exactly what I want }\end{array}$ & 194 & 3.59 & 1.21 \\
\hline $\begin{array}{l}\text { 9. It bothers me when the teacher uses an English word that I } \\
\text { don't know }\end{array}$ & 194 & 3.05 & 1.24 \\
\hline $\begin{array}{l}\text { 10. When I' m speaking in English, I feel uncomfortable if I can't } \\
\text { communicate my ideas clearly }\end{array}$ & 194 & 3.49 & 1.25 \\
\hline $\begin{array}{l}\text { 11. I don't like the fact that sometimes I can't find English words } \\
\text { that mean the same as some words in my own language }\end{array}$ & 194 & 2.66 & 1.26 \\
\hline $\begin{array}{l}\text { 12. One thing I don't like about reading in English is having to } \\
\text { guess what the meaning is }\end{array}$ & 194 & 2.00 & 1.03 \\
\hline Total & 194 & 3.09 & 1.08 \\
\hline
\end{tabular}


Table 2. Cluster of students according to their tolerance of ambiguity

\begin{tabular}{|l|l|l|l|l|l|l|l|l|}
\hline & $\mathrm{N}$ & Mean & $\mathrm{SD}$ & Std. Error & $\begin{array}{l}\text { 95\% CI for } \\
\text { Mean } \\
\text { (Lower } \\
\text { Band) }\end{array}$ & $\begin{array}{l}\text { 95\% CI } \\
\text { for Mean } \\
\text { (Upper } \\
\text { Band) }\end{array}$ & Minimum & Maximum \\
\hline High & 24 & 19.5 & 3.0205 & .6165 & 18.3079 & 20.8588 & 12.00 & 24.00 \\
Moderate & 110 & 38.2 & 6.3779 & .6081 & 37.0311 & 39.4416 & 25.00 & 47.00 \\
Low & 60 & 52.5 & 3.5054 & .4526 & 51.5944 & 53.4056 & 48.00 & 60.00 \\
Total & 194 & 40.3 & 11.3967 & .8182 & 38.7264 & 41.9540 & 12.00 & 60.00 \\
\hline
\end{tabular}

Table 3. Student grouping illustrated in percentage of AT

\begin{tabular}{|l|l|l|l|l|}
\hline & Frequency & Percent & Valid Percent & Cumulative Percent \\
\hline High & 24 & 12.4 & 12.4 & 12.4 \\
Moderate & 110 & 56.7 & 56.7 & 69.1 \\
Low & 60 & 30.9 & 30.9 & 100.0 \\
& & & & \\
Total & 194 & 100.0 & 100.0 & \\
\hline
\end{tabular}

Table 4. Diffrences between three AT clusters

\begin{tabular}{|l|l|l|l|l|l|}
\hline & $\begin{array}{l}\text { Sum of } \\
\text { Squares }\end{array}$ & df & Mean Square & F & Sig. \\
\hline Bewteen Groups & 19698.859 & 2 & 9849.429 & 350.410 & .000 \\
Within Groups & 5368.688 & 191 & 28.108 & & \\
Total & 25067.546 & 193 & & & \\
\hline
\end{tabular}

Table 5. Gender differences in ambiguity tolerance

\begin{tabular}{|l|l|c|l|l|l|l|l|l|}
\hline & Gender & $\mathrm{N}$ & Mean & $\mathrm{SD}$ & $\begin{array}{r}\text { Mean } \\
\text { Difference }\end{array}$ & $\mathrm{t}$ value & $\mathrm{df}$ & Sig. \\
\hline $\begin{array}{l}\text { Ambiguity } \\
\text { Score }\end{array}$ & Female & 160 & 3.3803 & .4032 & .2295 & 3.098 & 158 & .002 \\
\hline $\begin{array}{l}\text { Ambiguity } \\
\text { Score }\end{array}$ & Male & 34 & 3.1420 & .5235 & .2295 & 3.098 & 158 & .002 \\
\hline
\end{tabular}


Table 6. Distribution of male and females to different tolerance groups

\begin{tabular}{|c|c|c|c|c|c|c|}
\hline & & & high & moderate & low & Total \\
\hline Sex & Male & $\begin{array}{l}\text { Count } \\
\text { Expected Count } \\
\% \text { within sex } \\
\% \text { within Gsum } \\
\% \text { of total }\end{array}$ & $\begin{array}{l}5 \\
4.2 \\
14.7 \% \\
20.8 \% \\
2.6 \%\end{array}$ & $\begin{array}{l}16 \\
19.3 \\
47.1 \% \\
14.5 \% \\
8.2 \%\end{array}$ & $\begin{array}{l}13 \\
10.5 \\
38.2 \% \\
21.7 \% \\
6.7 \%\end{array}$ & $\begin{array}{l}34 \\
34.0 \\
100.0 \% \\
17.5 \% \\
17.5 \%\end{array}$ \\
\hline Sex & Female & $\begin{array}{l}\text { Count } \\
\text { Expected Count } \\
\% \text { within sex } \\
\% \text { within Gsum } \\
\% \text { of total }\end{array}$ & $\begin{array}{l}19 \\
19.8 \\
11.9 \% \\
79.2 \% \\
9.8 \%\end{array}$ & $\begin{array}{l}94 \\
90.7 \\
58.8 \% \\
85.5 \% \\
48.5 \%\end{array}$ & $\begin{array}{l}47 \\
49.5 \\
29.4 \% \\
78.3 \% \\
24.2 \%\end{array}$ & $\begin{array}{l}160 \\
160.0 \\
100.0 \% \\
82.5 \% \\
82.5 \%\end{array}$ \\
\hline Total & & $\begin{array}{l}\text { Count } \\
\text { Expected Count } \\
\% \text { within sex } \\
\% \text { within Gsum } \\
\% \text { of total }\end{array}$ & $\begin{array}{l}24 \\
24.0 \\
12.4 \% \\
100.0 \% \\
12.4 \%\end{array}$ & $\begin{array}{l}110 \\
110.0 \\
56.7 \% \\
100.0 \% \\
56.7 \%\end{array}$ & $\begin{array}{l}60 \\
60.0 \\
30.9 \% \\
100.0 \% \\
30.9 \%\end{array}$ & $\begin{array}{l}194 \\
194.0 \\
100.0 \% \\
100.0 \% \\
100.0 \%\end{array}$ \\
\hline
\end{tabular}

Table 7. Chi-Square tests for differences between expected and observed frequencies in gender-based AT groups

\begin{tabular}{|l|l|l|l|}
\hline & Value & df & $\begin{array}{l}\text { Asymp. Sig. } \\
\text { (2-sided) }\end{array}$ \\
\hline Pearson Chi-Square & $1.569(\mathrm{a})$ & 2 & .456 \\
Likelihood Ratio & 1.555 & 2 & .460 \\
Linear-by-linear & .254 & 1 & .614 \\
Association & & & \\
N of Valid Cases & 194 & & \\
\hline
\end{tabular}

(a). 1 cells $(16.7 \%)$ have expected count less than 5 . The minimum expected count is 4.21 . 


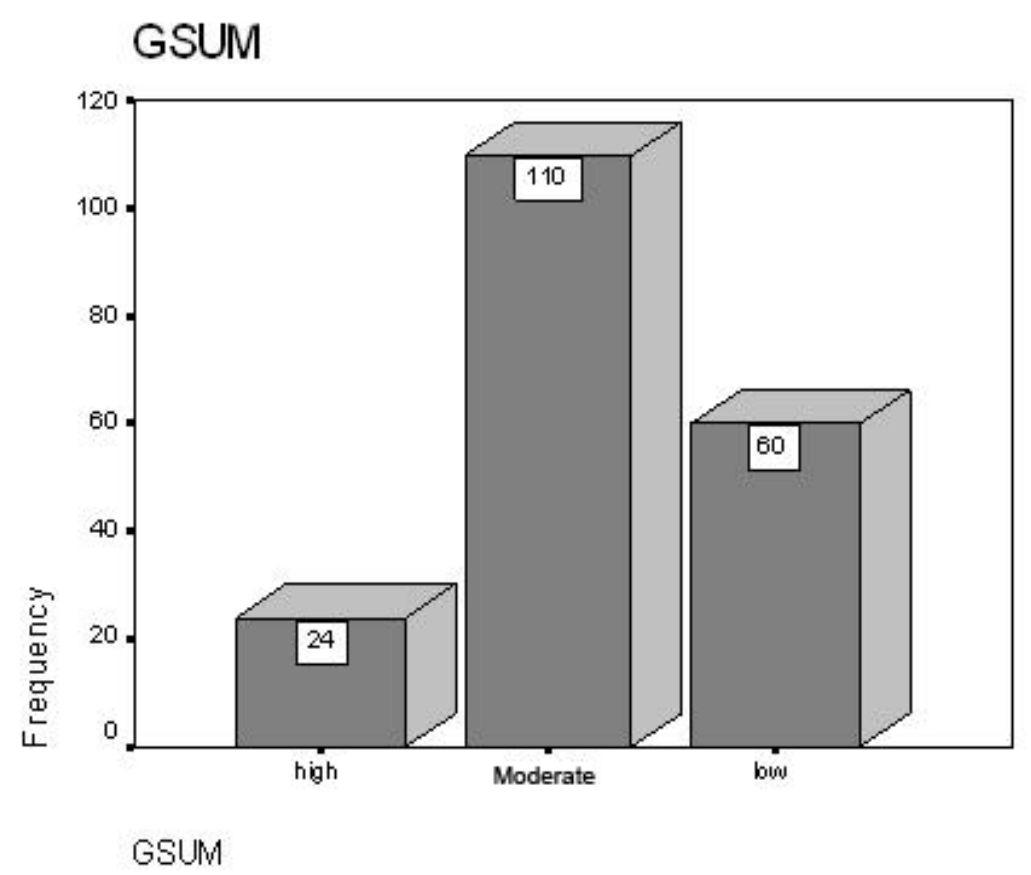

Figure 1. Iranian Undergraduates`ambiguity tolerance groups 